\title{
PROPUESTA PARA EL DESARROLLO PROFESIONAL DE LOS DOCENTES DE LAS ASIGNATURAS DEL AREA DE FORMACIÓN ESPECIFICA DEL DEPARTAMENTO DE EDUCACIÓN FISICA DE LA UNIVERSIDAD PEDAGOGICA NACIONAL
}

\author{
Álvaro José Gracia Díaz.*
}

\section{RESUMEN:}

En investigación que realicé sobre las Estrategias Didácticas utilizadas en las asignaturas del Área de Formación Específica del Departamento de Educación Física de la Universidad Pedagógica Nacional, a través de una entrevista estructurada y una ficha de observación, las cuales, me permitieron corroborar los planteamientos que maestros y alumnos hicieron en la entrevista estructurada, y además observé en el transcurso de los procesos metodológicos un énfasis en al reflexión consciente sobre las acciones motrices, para estimular y afectar las estructuras de pensamiento y la imaginación. La formación de grupos fundamentados en los centros de interés dentro de este saber específico para tratar de responder a las expectativas, motivaciones y necesidades de los alumnos.

El diálogo, la puesta en comunicación sobre aspectos divergentes, el respaldo y el respeto por los criterios de los demás fueron también factores predominantes en el desarrollo de las sesiones de clase de estas asignaturas.

Otro de los factores que es de vital importancia resaltar aquí es la toma de decisiones, definitivamente, se ha entendido que alrededor de ésta gira la evolución del ser puesto que, al tomarla implica compromiso consigo mismo, debido a que constituye que el alumno se determine y realice.

En la observación detallada de las clases esto se vio muy claro, un sinnúmero de posibilidades en donde se requiera elegir entre varias alternativas, que exigen la fortaleza para ser diferente y aceptar que se es diferente, esto significa capacidad de interactuar con otros individuos de manera que cada quien mantenga su independencia eliminando así, el dogmatismo intelectual.

\section{ORIENTACIÓN DE LA PROPUESTA}

Dentro de la entrevista estructurada se hicieron preguntas que indagaron sobre la forma, como se podía lograr el desarrollo profesional de los docentes de la Educación Física en la Educación Superior, para el mejoramiento de las estrategias didácticas y de los planteamientos hechos por profesores y alumnos surgió la necesidad de estructurar un plan continuo, permanente y eficaz de desarrollo profesional, que permita, no sólo la cualificación del docente sino el mejoramiento de la formación del futuro licenciado. Como resultado del trabajo de investigación, se presentaron planteamientos sobre: Cuáles eran las directrices o fundamentos de un plan de desarrollo profesional y cuáles y cómo debían organizarse, las distintas actividades para que este cumpla su verdadero objetivo.

De acuerdo a investigaciones y experiencias en el campo del desarrollo profesional del docente, éste no ha alcanzado la prioridad del mejoramiento de la labor pedagógica y en

\footnotetext{
* Profesor Universidad Pedagógica Nacional 
consecuencia de los alumnos, debido, en gran parte, a una concepción equivocada de los que debe ser la capacitación y la forma como ha venido dando, a través de cursos, seminarios, foros, alejados de la realidad del trabajo del docente, sin motivar a éstos a través de procesos de participación y sin contemplar un plan global e integral de formacion.

\section{¿QUÉ SE DEBE TENER PRESENTE PARA EL DESARROLLO PROFESIONAL?}

De estos resultados y la manifestación de profesores y alumnos en el entrevista estructurada surge la necesidad de concebir el desarrollo profesional del docente, en forma diferente, se plantea como se da la toma de conciencia por parte del profesional, mediante procesos de cambios autogestionados donde se logra a través de la reflexión e investigación la transformación de aspectos personales y profesionales, por lo tanto el desarrollo profesional debe tener presente lo siguiente:

Es un proceso de análisis discusión y reflexión de la práctica pedagógica y didáctica cotidiana, en la cual, se encuentran inmersos los maestros, pues la discusión sobre el quehacer educativo, le permitirá evolucionar y desarrollarse a través de un proceso más activo y creador.

Las alternativas de cualificación deben surgir de los propios maestros y de una tarea rigurosa, y consciente para la elaboración de su plan de autodesarrollo mediante la participación activa en proyectos de investigación alrededor de las actividades que orientan en el desarrollo de su labor educativa.

Es a través del cuestionamiento del quehacer educativo cotidiano, que se da la posibilidad de cambio de actitud de los maestros, pues les permite, el desarrollo de sus potencialidades creativas, para que puedan construir sus propias concepciones, recursos e instrumentos de trabajo.

\section{¿POR QUE DEBE PROPENDER EL DEPARTAMENTO DE EDUCACIÓN FÍSICA EN LO ACADÉMICO?}

El Departamento de Educación Física debe propender por acciones de tipo académico y administrativo, con relación a los primeros se recomienda:

- Propiciar sesiones periódicas de autoevaluación, las cuales se pueden organizar a través de lecturas, seminarios, en donde mediante la participación activa sea el mismo docente quien se dé cuenta de sus limitaciones y avances en el campo académico.

- Realizar reuniones periódicas con ponencias de los maestros de las asignaturas del Área de Educación Física Especifica, donde se den a conocer las experiencias y análisis en el uso de las estrategias didácticas.

- Formar grupos por deporte y sistematizar las estrategias didácticas que cada maestro utiliza para la orientación de su asignatura, y de acuerdo a sus posibilidades diseñar videos que sirvan como multiplicadores del conocimiento de éstas. 
- Como se están dando marcados avances y progresos para el cambio de actitud del maestro frente a los fenómenos socioculturales que gravitan sobre su práctica pedagógica y didáctica de las asignaturas de la Teoría y Método de los Deportes de área de Formación Específica es necesario proponer espacios de reflexión sobre el trabajo cotidiano de los docentes, para analizar críticamente la cultura y el saber especifico que se imparte.

- Estimular a los profesores para el uso de estrategias didácticas, que propendan: Por el desarrollo grupal e individual, en la búsqueda de hacer una realidad la formación integral del futuro licenciado en Educación Física. Y porque los alumnos sean gestores de sus propios procesos de desarrollo profesional, mediante el quehacer consciente de su propia práctica pedagógica y didáctica, y la apropiación de las habilidades profesionales de su saber especifico, y que comprendan que la experiencia personal, junto con la de sus compañeros docentes conforman también su aprendizaje.

- Cada maestro debe convertir su asignatura del área de Formación Específica, en un proyecto de investigación que signifique continua exploración y contrastación entre la teoría y la práctica, en la búsqueda de nuevos constructos, que finalmente conllevan a su presentación en publicaciones, participación en seminarios y congresos nacionales e internacionales de Educación Física.

- Los maestros deben conocer a través de procesos de autoevaluación, cuales son sus aciertos, logros, dificultades y limitaciones en su trabajo y luego de esta reflexión y análisis hacer los replanteamientos o refuerzos de sus concepciones filosóficas, epistemológicas, psicológicas, pedagógicas y didácticas, así, como de sus prácticas pedagógicas.

En resumen, el desarrollo profesional debe propender la autoformación de una actitud y espíritu crítico reflexivo y participativo del maestro; por la toma de conciencia en su labor educativa, a través de la autoevaluación rigurosa; por la pérdida del temor al cambio, al cuestionamiento sobre la rutinización y esquematización de su quehacer; por la cualificación de la formación pedagógica y didáctica; por el conocimiento de las realidades socioculturales en la s que se desempeña, para lograr la coherencia de los programas con las necesidades educativas, con las innovaciones en los procesos de aprendizaje. Para llegar a cumplir con estos propósitos un plan de desarrollo profesional debe hacerse en el sitio de trabajo de los interesados y a través de actividades tales como: proyectos de investigación, talleres, seminarios realizados en forma continua con la participación activa de los interesados e involucrados en un plan global de desarrollo de la institución.

\section{¿QUÉ SE DEBE TENER EN CUENTA PARA EL DESARROLLO PROFESIONAL DE LOS MAESTROS DEL ÁREA DE FORMACIÓN ESPECÍFICA DEL DEPARTAMENTO DE EDUCACIÓN FÍSICA?}

Particularmente, para el desarrollo profesional de los maestros del área de Formación Especifica del Departamento de Educación Física se deben tener en cuenta, los siguientes aspectos, partir:

- De un diagnóstico previo de las necesidades e intereses académicos de los profesores es del Departamento. 
- Del conocimiento de las políticas del desarrollo del mismo, para que el plan de desarrollo profesional no sea una rueda suelta que se da a través de recursos ocasionales o por la participación en seminarios, congresos y paneles de la Educación Física, el Deporte y la Recreación, sino que a través de éste se logre que el plan general de desarrollo del Departamento alcance sus objetivos.

- De los directivos y profesores del Departamento de Educación Física, a quienes les corresponde liderar el proceso del desarrollo profesional, involucrando a todos aquellos maestros que tengan interés, actitud y compromiso con esta búsqueda de cualificación, y motivando a todos aquellos que se sienten comprometidos, a que lo logren, para cumplir con los presupuestos de lo que debe ser un plan de desarrollo profesional del docente, los cuales se han esbozado someramente. 